\title{
Determination of Polycyclic Aromatic Hydrocarbons by High-Performance Liquid Chromatography-Particle Beam-Mass Spectrometry
}

\author{
Raj P. Singh, Ian D. Brindle, Timothy R. B. Jones, and Jack M. Miller \\ Chemistry Department, Brock University, St. Catharines, Ontario, Canada
}

Mikio Chiba

Agriculture Canada, Vineland Station, Ontario, Canada

In this article, we report a high-performance liquid chromatography-particle beam-mass spectrometric (HPLC-PB-MS) method for the determination of polycyclic aromatic hydrocarbons (PAHs). The PB interface consists of a concentric ultrasonic nebulizer with temperature-controlled desolvation chamber and a three-stage momentum separator. The HPLCPB-MS method showed greater sensitivity for PAHs with mulecular weights above 178 than for those PAHs with molecular weights below 178. The percent relative standard deviations for the determination of $0.5 \mathrm{ng}$ chrysene, $1.0 \mathrm{ng}$ dibenzo[a,h]anthracene, $1.0 \mathrm{ng}$ benzo[g, $h, i]$ perylene, and $2.5 \mathrm{ng}$ coronene were $20 \%, 2.5 \%, 13.7 \%$, and $6 \%$, respectively. The detection limits at signal/noise $=3$ were $0.2 \mathrm{ng}$ for chrysene, $1.0 \mathrm{ng}$ for dibenzo[a,h]anthracene, $0.5 \mathrm{ng}$ for benzo[g,h,i]perylene, and $1.5 \mathrm{ng}$ for coronene. (J Am Soc Mass Spectrom 1993, 4, 898-905)

$\mathrm{P}$ olycyclic aromatic hydrocarbons, commonly known as PAHs, are widespread in the environ ment [1-4]. Since several of these compounds are well-known carcinogens, their determination in water, air, sediment, biota, and foodstuffs is required routinely. High-performance liquid chromatography (HPLC) with UV and fluorescence detection [5-6] and gas chromatography-mass spectrometry (GC-MS) [7-9] are normally used for the determination of low levels of PAHs in various matrices. However, none of these methods is free of problems. The most serious problem of HPLC/UV is that it relies on a single parameter (i.e., retention time) for the identification of solutes. On the other hand, GC-MS is reported to give poor sensitivity for late-eluting PAHs [10]. Mass spectrometry, which allows the analyst to acquire considerable structural information, may be able to solve the problem of identification of solute if used as a detector in combination with HPLC.

Because of the potential advantage of HPLC-MS over conventional HPLC/UV and GC-MS methods, outlined above, serious efforts have been made in recent years to interface an HI'LC with the mass spectrometer [11-13]. These efforts include direct liquid

Address reprint requests to Ian Brindle, Chemistry Department, Brock University, St. Catharines, Ontario L2S 3A1, Canada. introduction (DLI) [14], thermospray [15-19], electrospray [20-22], ion evaporation [13], nebulization into an atmospheric pressure cherrical ionization (APCI) source [23-28], and particle-beam (PB) interfaces [29-31]. The particlc-bcam interface allows separation of the analytes from the HPLC eluent and delivers them to a conventional electron-impact (EI) source, thus generating library-searchable EI spectra of the analytes. This makes PB-MS a valuable technique among HPLC-MS methods.

The PB interface was originally developed by Browner and Williums and co-workers $[29,30]$ as a helium-nebulized, monodisperse-aerosol-generating analyzer. Normally, in the PB interface, HPLC effluent is pneumatically nebulized into a desolvation chamber. Analyte molecules in the solvent stream nucleate to form submicrometer particles in the desolvation chamber. These particles are separated from the solvent vapor molecules in a two- or three-stage momentum separator and are subsequently transported to the ion source of the mass spectrometer.

At the present time, a number of $\mathrm{PB}$ interfaces are commercially available, normally with a concentric pneumatic nebulizer system [29-36]. The sample is nebulized by helium at flow rates of $0.5-10 \mathrm{~L} \mathrm{~min}^{-1}$. These interfaces can transport HPLC effluents at flow rates ranging from $0.1 \mathrm{~mL} \mathrm{~min}{ }^{-1}$ to $1.0 \mathrm{~mL} \mathrm{~min}^{-1}$ to 
the mass spectrometer ion source. An ultrasonic nebulizer with controlled heating of the desolvation chamber was also developed by Ligon and Dorn [31]. In this $P B$ interface, an ultrasonic nebulizer was used to nebulize HPLC effluent delivered externally at an angle to the tip of the ultrasonic horn. The dispersion gas was delivered axially through the ultrasonic nebulizer tip. A three-stage momentum separator was used to remove HPLC solvent and dispersion gas from the central PB. This interface was especially designed to connect an HPLC, running at high eluent flow rates $(>1.0$ $\mathrm{mL} \min ^{-1}$ ), to a magnetic-sector mass spectrometer.

In recent years, several articles have reported the use of PB-MS for the determination of organic compounds, especially polar compounds such as caffeine, pesticides, and pharmaceutical compounds [29-41]. However, to our knowledge, PB-MS has not been used for the determination of PAHs. Therefore, the purpose of this article was to develop an HPLCPB-MS method for the determination of PAHs. The PB interface, used here, was a modified version of the $P B$ interface originally designed by Ligon and Dorn [31]. The modified interface consisted of a concentric ultrasonic nebulizer with temperature-controlled desolvation chamber and a three-stage momentum separator.

\section{Experimental}

\section{Chemicals}

Acenaphthylene, acenaphthene, fluorene, phenanthrene, chrysene, dibenzo[a,h]anthracene, dibenzo$[g, h, i]$ perylene, and coronene were obtained from Aldrich Chemical Company (Milwaukee, WI). HPLCgrade ammonium acetate was obtained from Fisher Scientific (Fair Lawn, NJ).

\section{Solvents}

HPLC-grade acetonitrile and methanol were obtained from Caledon Laboratories (Georgetown, Ontario, Canada). Water was distilled in glass in the laboratory.

\section{High-Performance Liquid Chromatograph}

The liquid chromatograph used was a Waters 600-MS system controller with a Waters 441 UV/VIS absorbance detector. Separation of PAHs was achieved on Vydac reversed phase C-18, $5 \mu, 15 \mathrm{~cm} \times 4.6 \mathrm{~mm}$ (i.d.) column and Phenomenex Ultracarb $5 \mu$ ODS (20) $150 \times 2 \mathrm{~mm}$ and Ultracarb $3 \mu$ ODS (20) $150 \times 2 \mathrm{~mm}$ columns. The mobile phases used were acetonitrile, methanol, and methanol containing a small amount of ammonium acetate. The UV detector was operated at $254 \mathrm{~nm}$, with detector sensitivity of 0.05 AUFS. Peaks were integrated on a Hewlett Packard HP 3396 Series II integrator. The total system was operated at ambient temperature.

\section{Particle-Beam Interface}

A schematic of the PB interfacc is shown in Figure 1. The design of the ultrasonic head, desolvation chamber, nozzle, and three-stage momentum separator, up to the second stage, was similar to that reported by Ligon and Dorn [31], except that the effluent from the HPLC was delivered coaxially via a silica capillary $(0.075 \mathrm{~mm}$ i.d., $0.34 \mathrm{~mm}$ o.d.) and nebulized at the exit end of the ultrasonic head by a fast, concentric flow of helium gas at $900 \mathrm{~mL} \min ^{-1}$. The transducer was situated in the body of the ultrasonic horm (indicated by $c$ in Figure 1). The end of silica capillary was positioned about $2 \mathrm{~mm}$ behind the tip of the ultrasonic head (i.d. at tip = 1 mum). The transfer tube, which included a third stage of vacuum separator, was based on the Kratos PB interface design. The two diametrically opposed pumping ports of the first stage were connected to a Welch Duo Seal vacuum pump with $500 \mathrm{~L} \mathrm{~min}^{-1}$ pumping speed. The ports of the second identical stage were connected to an Edwards highvacuum pump with $300 \mathrm{~L} \mathrm{~min}^{-1}$ pumping speed. The third, and last, stage was pumped by an Edwards high-vacuum pump with $15 \mathrm{U} \mathrm{L} \mathrm{min}^{-1}$ pumping speed. The heated walls of the source provided thermal energy for instant volatilization of the particles. The ionization of the gaseous solute from the volatilized particles occurs by EI.

\section{Mass Spectrometer}

A Kratos Concept IS double-focusing mass spectrometer (Kratos Analytical, Urmston, Manchester, UK) (E/B configuration) employing an EI chemical ionization (EI/CI) source was used for mass spectrometric analyses. The instrument was controlled by a Kratos DS 90 Data General Eclipse-based computer system. A Kratos Mach 3 data system running on a SUN SPARCstation was used for further data workup. For all studies, a nominal resolving power of 1000 was used. The stan-

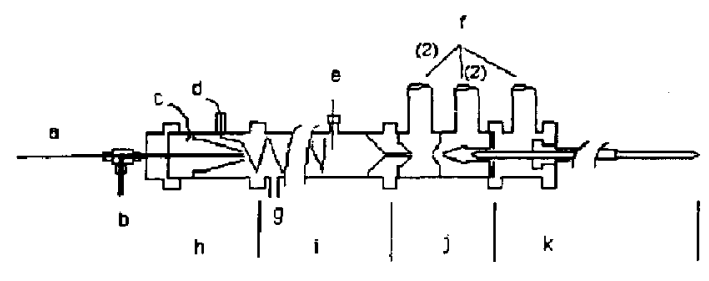

Particle Beam Schematic

a. HPLC efiluent capillary
b. Helium gas iniet
c. Ulbasonic horn
d. Desolvation heater
e. Thermocouple
f. Roughing purmp connectlons

g. Somentwaste

h. Ultrasonic jet assembly

i. Desolvation chamber

j. Skimmer stages 1 and 2

k. Final sk mmer and bansfer line

i. Roughing purnp connectlons

Figure 1. Schematic PB interface with concentric ultrasonic pneumatic nebulizer, controlled heating of desolvation chamber and three stage mornentum separator. 
dard EI/CI source, operated at temperatures 220-300 ${ }^{\circ} \mathrm{C}$ and $6 \mathrm{kV}$ accelerating potential, was used. The scan rate was 3.0 seconds per decade for full scan acquisition. Selected ion monitoring (SIM) acquisitions were made under the same instrumental conditions as described above using a $0.6-1.0 \mathrm{sec}$ cycle time for the PAH groups of interests. The PB-MS system was tuned and mass calibrated with perfluorokerosene (PFK).

\section{Results}

\section{Particle-Beam Interface}

Since we were going to use a magnetic-sector mass spectrometer, we chose to build a nebulizing system similar to that of Ligon and Dorn [31]. However, the interface described by Ligon and Dorn did not work for us, as we experienced problems of signal reproducibility, apparently caused by the misalignment among aerosol beam, nozzle, and the three-stage momentum separator. While, in theory, the Ligon and Dorn design should give satisfactory results, as constructed by our shops, the nebulizer alignment with the rest of the interface was critical. To confirm this, we constructed a clean plastic desolvation chamber to observe the spray profile of the target area. The results of this experiment indicated that much of the aerosol beam was not focused on the nozzle (as it was targeting different parts of the nozzle cone) due, perhaps, to the tendency of the tangential capillary to wander when the ultrasonic horn was under power. To solve this problem, we redesigned the ultrasunic inlet to accommodate a concentric sample-delivery capillary. The modified nebulizing system with concentric pneumatic ultrasonic nebulizer (Figure 1) resulted in immediate improvements in the alignment stability and signal reproducibility. Although the exact mechanism by which oscillation of the transducer is coupled to the liquid in the concentric pneumatic ultrasonic nebulizer is not known, the sensitivity of the signals clearly illustrate the function of the ultrasonic horn in the modified nebulizer. With the ultrasonic horn turned off, no signal for $20 \mathrm{ng}$ chrysene was detected, whereas the same quantity gave 400,000 peak area counts with the ultrasonic horn under power. The stability of the ultrasonic horn and the reproducibility of results suggest that the transducer, which has an energy of about $2 \mathrm{~W}$, is being cooled primarily by the expanding gas.

\section{Response of $P B-M S$ for Different PAHs}

Figure 2 shows the relative responses of different PAHs obtained by PB-MS. The samples were injected directly into methanol streams flowing at a rate of 0.3 $\mathrm{mL}$ min $^{-1}$. It is quite obvious from Figure 2 that the sensitivity of the PB-MS method was greater for PAHs with molecular weights $>178$ than for PAHs with molecular weights $<178$. Since the GC-MS method is

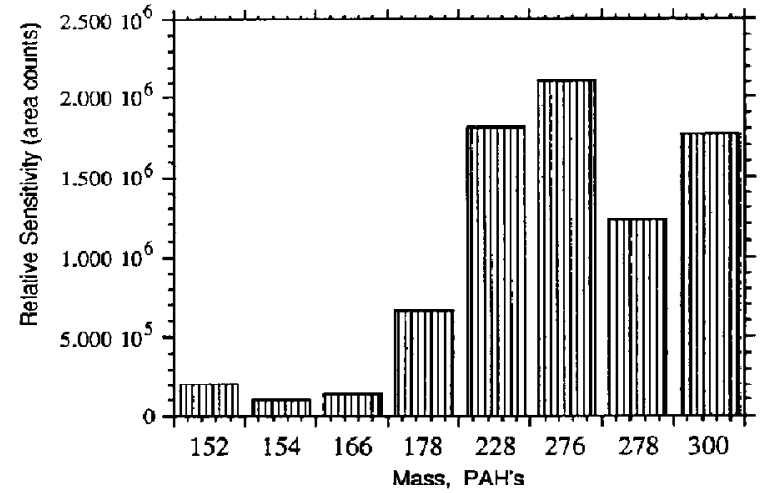

Figure 2. HPLC-PB-MS response for different PAHs; $152=$ acenaphthylene, $154=$ acenaphthene, $166=$ fluorene, $178=$ phenanthrene, $228=$ chrysene, $276=$ benzolg,h,i]perylene, 278 $=$ dibenz $[\mathrm{a}, \mathrm{h}]$ anthracene, and $300=$ coronene.

reported to give relatively poor sensitivity for late-eluting PAH peaks [4], the strong signals of chrysene (228), dibenzo[a,h]anthracene (278), benzo[g,h,i]perylene (276), and coronene (300), shown in Figure 2, prompted us to concentrate our efforts on developing an HPLC-PB-MS method for the determination of relatively high-molecular-weight PAHs.

The sensitivity of the PB interface was optimized for the solvent of the HPLC mobile phase, eluent flow rate, and source temperature. Optimization of the sensitivity of solute was normally carried out by using chrysene, since, as will be reported later, chrysene showed higher signal sensitivity than other PAHs.

\section{Effect of Solvent of the Mobile Phase on Chrysene Signal}

For HPLC separation of PAHs, normally, acetonitrile and methanol solvents were used in the mobile phase. The sensitivity of the chrysene signal was compared using mobile-phase solvents acetonitrile and methanol under conditions of direct flow injection (without a column). The representative mass chromatograms of chrysene in acetonitrile and methanol solvents are shown in Figure 3. Because methanol provided higher sensitivity for the chrysene signal compared with acetonitrile under identical operating conditions, methanol was used as the mobile phase in all the determinations reported in this article.

\section{Effect of Eluent Flow Rate on Chrysene Signal and Selection of HPLC Column}

Since the dispersion gas, helium, was used at a fixed flow rate of $0.9 \mathrm{~L} \mathrm{~min}^{-1}$, the sensitivity of the chrysene signal was optimized by changing the eluent flow rate. The results of these experiments revealed that the sensitivity of the chrysene signal between flow rates 


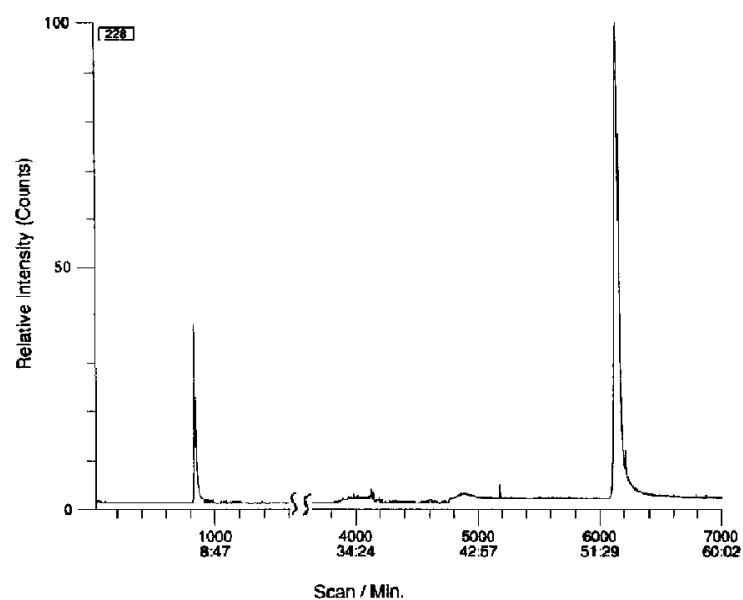

Figure 3. Effect of eluent (solvent) on $20 \mathrm{ng}$ signal of chrysene: Signal 1 is with MeCN (injection was made at approximately 6.3 min); signal 2 is with $100 \% \mathrm{MeOH}$ (MeOH as eluent was started at about $30 \mathrm{~min}$, injection was made at approximately $51.3 \mathrm{~min}$ );

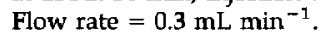

100 and $300 \mu \mathrm{L}$ min $^{-1}$ remained apparently constant (peak area counts $=1.2-1.5 \times 10^{6}$ ). However, the sensitivity of the chrysene signal decreased substantially at eluent flow rates higher than $300 \mu \mathrm{L} \mathrm{min}{ }^{-1}$. The signal counts decreased from $1.3 \times 10^{6}$ at a flow rate of $300 \mu \mathrm{L} \mathrm{min}$ min $^{-1}$ to $0.3 \times 10^{6}$ at a flow rate of $400 \mu \mathrm{L}$ $\min ^{-1}$. Therefore, to increase the sensitivity, minibore columns ( $2 \mathrm{~mm}$ i.d.) were used for the separation and determination of PAHs because of their favorable flow rates and faster speed (faster elution behavior) compared with conventional ( $4.6 \mathrm{~mm}$ i.d.) HPLC columns. Figure 4 shows the comparison of chromatograms, depicting the separation of chrysene, dibenzo[ $\left.\mathrm{a}_{\mathrm{a}} \mathrm{h}\right]$ anthracene, benzo[g,h,i]perylene, and coronene on a 2 $\mathrm{mm}$ i.d. column (with $0.3 \mathrm{~mL} \mathrm{~min}{ }^{-1}$ flow rate) and 4.6 $\mathrm{mm}$ i.d. column (with flow rate $1.0 \mathrm{~mL} \mathrm{~min}{ }^{-1}$ ). It is clear from Figure 4 that the $2 \mathrm{~mm}$ i.d. column not only showed a faster separation of PAHs but also showed high sensitivity for all four PAHs compared with the $4.6 \mathrm{~mm}$ i.d. column. It is also interesting to note that the order of elution changes between the two columns.

\section{Effect of Source Temperature on Chrysene and Coronene Signals}

Figure 5 shows the effect of mass spectrometer source temperature on the intensity of chrysene $(m / z=228)$ and coronene $(m / z=300)$ signals. Although source temperature did not have any effect on the sensitivity of the chrysene signal, a higher sensitivity and better peak shape for coronene was obtained at a temperature close to $280{ }^{\circ} \mathrm{C}$, apparently due to the lower volatility of coronene (m.p. $=428{ }^{\circ} \mathrm{C}$ ) than chrysene (m.p. $=225^{\circ} \mathrm{C}$ ). Therefore, determinations involving coronene and other high molecular weight PAHs were made at a source temperature of $275-280{ }^{\circ} \mathrm{C}$.

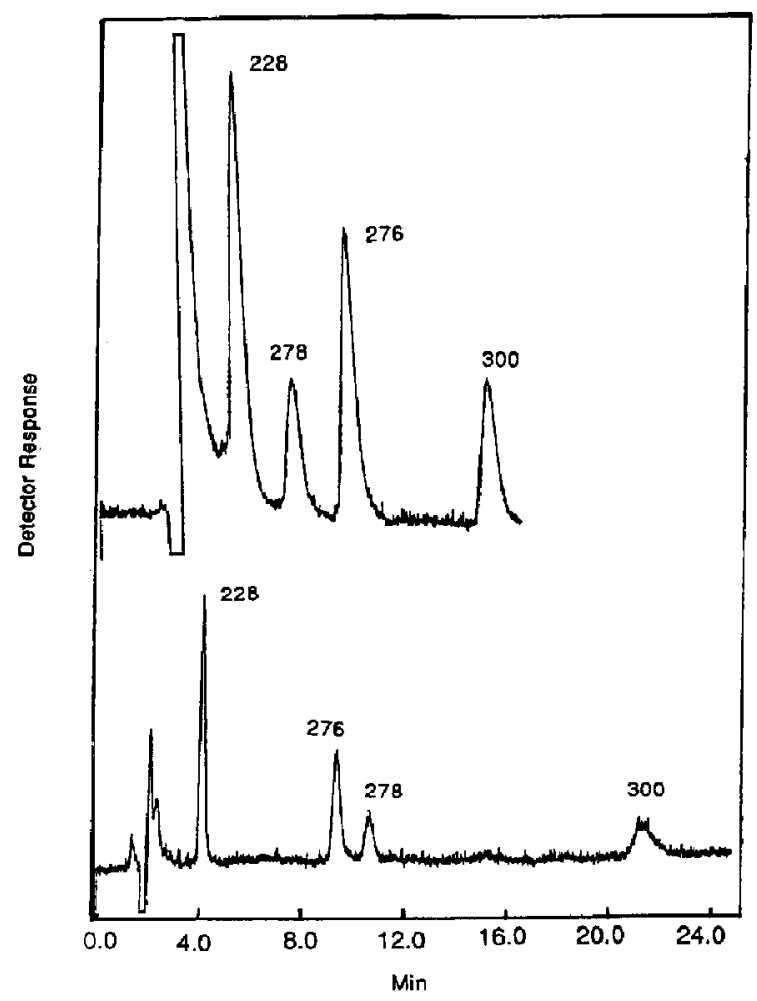

Figure 4. HPLC-UV chromatograms showing the separation of $5 \mathrm{ng}$ chrysene (228), $10 \mathrm{ng}$ dibenz $[\mathrm{a}, \mathrm{h}]$ anthracene (278), $10 \mathrm{ng}$ benzo[g,h,i]perylene (276), and $25 \mathrm{ng}$ coronene (300); upper chromalogram with $15 \mathrm{~cm} \times 2 \mathrm{~mm}, 3 \mu, C-18$ silica column; lower chromatogram with $15 \mathrm{~cm} \times 4.6 \mathrm{~mm}, 5 \mu, \mathrm{C}-18$ silica column; eluent $=100 \% \mathrm{MeOH}$; Flow rate $=0.3 \mathrm{~mL} \mathrm{~min}{ }^{-1}$ for $2 \mathrm{~mm}$ column and $1.0 \mathrm{~mL} \mathrm{~min}{ }^{-1}$ for $4.6 \mathrm{~mm}$ column.

Separation and Determination of Chrysene, Dibenzola,h]anthracene, and Benzolg,h,ilperylene by Full-Scan Acquisition

Since the HPLC-PB-MS system showed good sensitivity for PAHs with molecular weights greater than 178 ,

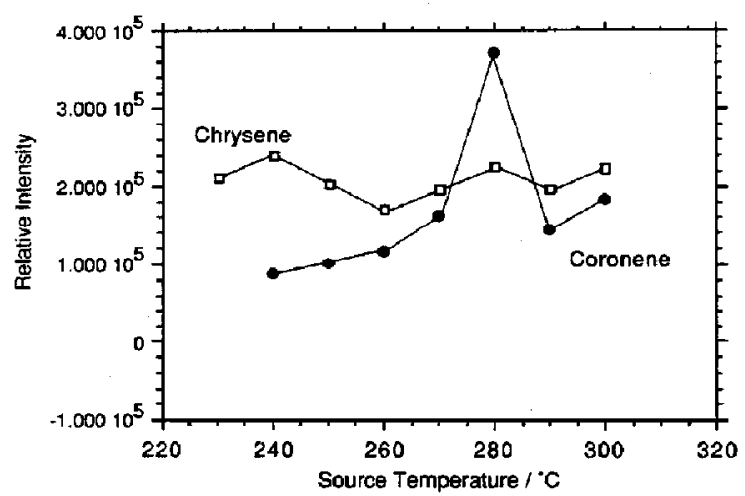

Figure 5. Effect of source temperature on the sensitivity of chrysene and coronene. 
efforts were made to develop suitable conditions for their determination by the full-scan acquisition method. Figure 6 shows the effect of methanol flow rate on the intensity of chrysene, dibenzol[a,h]anthracene, and benzo[g,h,i]perylene signals. As shown in Figure 6, the effect of eluent flow rate through the column on the intensity of the signals of PAHs appears to be different from the effect observed when the column was bypassed. In fact, the intensity of the signals increased with the increase in eluent flow rate through the column, perhaps due to relatively sharper elution of PAHs at high flow rates than at low flow rates.

Figure 7 shows the total-ion-current mass chromatogram for the separation of $\mathbf{2 0} \mathrm{ng}$ each of chrysene, dibenzo[ $a, h]$ anthracene, and benzol $g, h, i]$ perylene. Peak 1 is due to an impurity of mass 178 . Peaks 2,3 , and 4 are due to chrysene, dibenzola,h]anthracene and benzo[g,h,i]perylene, respectively. The mass chromatogram was not smoothed and showed the typical noise level. The spectrum of peak 2 (Figure 8 ) shows a clear molecular ion at $m / z 228$. The spectrum matched favorably with the library spectrum of chrysene (lower spertrum, Figure 8). This confirms that no degradation of chrysene has occurred when passed through the PB interface and that the fragmentation pattern is consistent with the molecular structure and reference EI spectrum of chrysene. Peaks 3 and 4 also generated high-quality spectra for dibenzo[a,h]anthracene and benzolg,h,i]perylene. These results suggest that the quality of EI spectra obtained for PAHs, after their determination by HPLC-PB-MS, are sufficiently good for identification of these compounds by searching the library.

The detection limits $(3 \times$ noise $)$ by full-scan acquisition for chrysene, dibenzo[a,h]anthracene and benzo[g,h,i]perylene were estimated at $2.0 \mathrm{ng}, 4.0 \mathrm{ng}$, and $2.0 \mathrm{ng}$, respectively.

\section{Effect of Ammonium Acetate in the Eluent on Sensitivity}

It has been reported that addition of small amounts of ammonium acetate in the eluent produced substantial enhancement in the signals of some analytes during their determination by HPLC-PB-MS [27, 34]. Consequently, the effect of ammonium acetate in methanol on the signal intensity of chrysene was investigated. The results of these experiments showed that addition of a small amount of ammonium acetate (at $0.05 \mathrm{~g}$ per $100 \mathrm{~mL}$ ) in methanol enhanced the signal of chrysene by approximately 2.5 times. Ammonium acetate in amounts larger than $0.05 \mathrm{~g}$ per $100 \mathrm{~mL}$, however, showed no further enhancement of the chrysene signal.

Figure 9 shows the effect of ammonium acetate on signal sensitivities of chrysene, dibenzo[a,h]anthracene, benzo[g,h,i]perylene and coronene. Again, it is clear from the mass chromatograms that addition of $0.05 \mathrm{~g} / 100 \mathrm{~mL}$ ammonium acetate in methanol substantially enhanced the signal of all four PAHs.

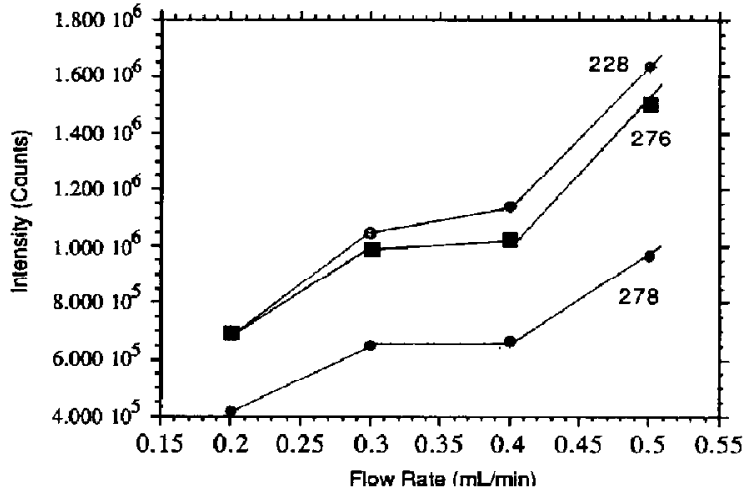

Figure 6. Effect of $\mathrm{MeOH}$ flow rate (through the column) on the signals of masses 228, 276 and 278; column $=15 \mathrm{~cm} \times 2 \mathrm{~mm}, 5$ $\mu, \mathrm{C}-18$ silica, eluent $=100 \%$ methanol.

Although enhancement in the signal of analytes by the addition of ammonium acetate in the eluent is not clearly understood, it is commonly believed that ammonium acetate may enhance the rate of nucleation process of solutes to form submicrometer particles, which can be transported to the mass spectrometer ion source.

Separation and Determination of Chrysene, Dibenzola,hlanthracene, Benzolg, $h, i]$ perylene, and Coronene by Selected Ion Monitoring

The determination of chrysene, dibenzo[a,h]anthracene, benzo[g,h,i]perylene, and coronene was also investigated by selected ion monitoring. Figure 10 shows the single-ion-monitoring trace of a mixture containing

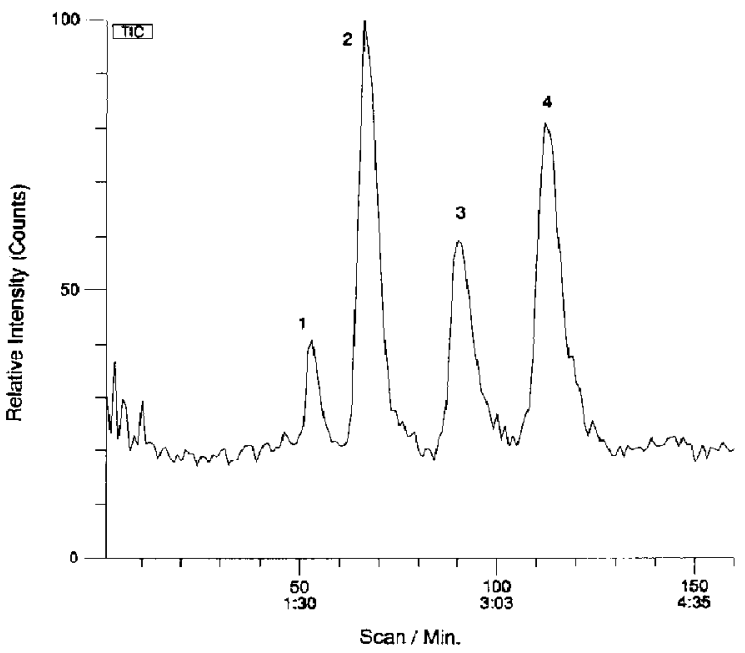

Figure 7. Total ion current mass chromatogram of $20 \mathrm{ng}$ each of 2 = chrysene $(228), 3=$ dibenz $[a, h]$ anthracene $(278)$ and $4=$ benzo[g,h,i]perylene (276); column $=15 \mathrm{~cm} \times 2 \mathrm{~mm}, 5 \mu, \mathrm{C}-18$ silica, eluent $=100 \%$ methanol, flow rate $=0.5 \mathrm{~mL} \mathrm{~min}^{-1}$. Note: Peak 1 is an impurity with $m / z 178$ 


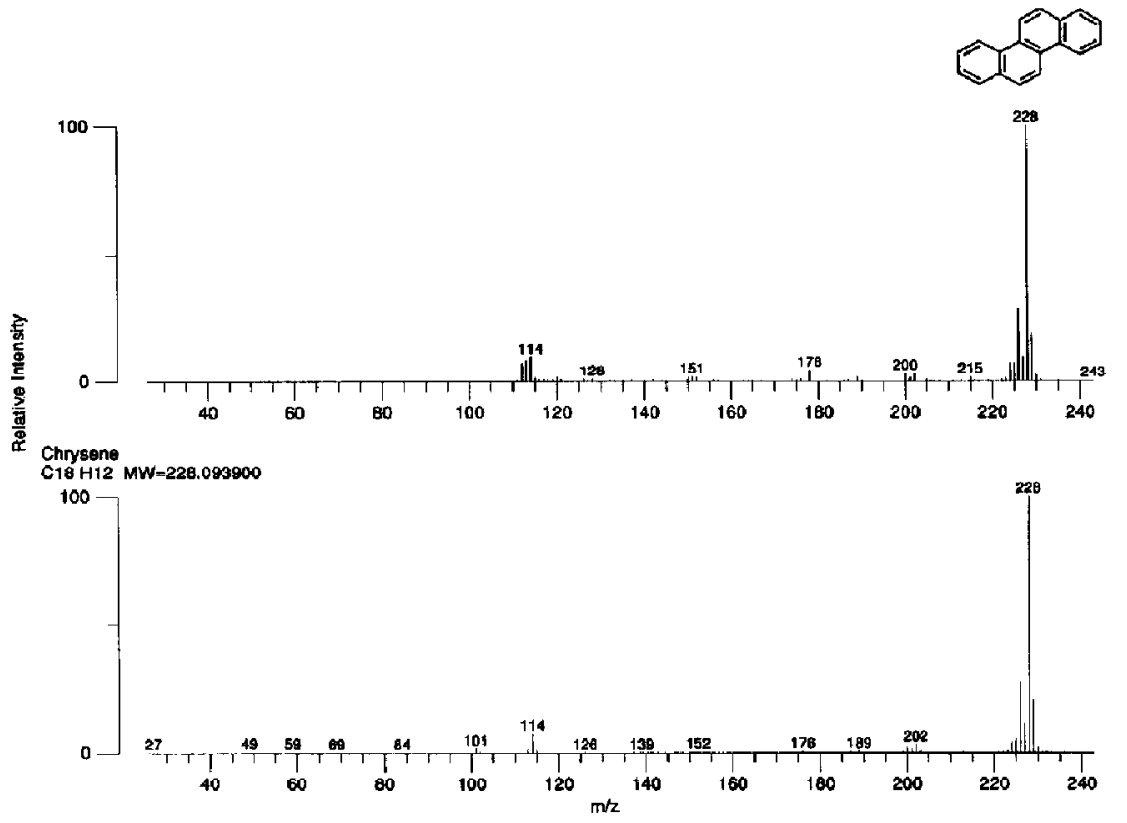

Figure 8. EI mass spectrum of peak 2, $20 \mathrm{ng}$ chrysene (upper) with library spectrum (lower).

$0.5 \mathrm{ng}$ chrysene, $1.0 \mathrm{ng}$ of dibenzola,hjanthracene and benzo[g,h,i]perylene, and $2.5 \mathrm{ng}$ of coronene. On the basis of three consecutive injections, as shown in Figure 10, we have calculated the reproducibility of the determination of these PAHs and their signal-to-noise ratio. The percent relative standard deviations calculated for chrysene, dibenzo[a,h]anthracene, benzo[g,h,i]perylene, and coronene were, respectively, $20 \%, 2.5 \%, 13.7 \%$, and $6 \%$. The signal-to-noise ratios were 10 for chrysene, 2.5 for dibenzo[a,h]anthracene, 6 for benzo[g,h,i]perylene, and 4.5 for coronene. On the basis of these data, the estimated detection limits were as follows: $200 \mathrm{pg}$ for chrysene, $\mathbf{1} \mathrm{ng}$ for dibenzo $[a, h] a n t h r a c e n e, 500 \mathrm{pg}$ for benzo[g,h,i]perylene, and 2 ng for coronene.

The last chromatogram in Figure 10 shows the trace of single ion monitoring of the same mixture used in the first three chromatograms [i.e., the mixture contain-

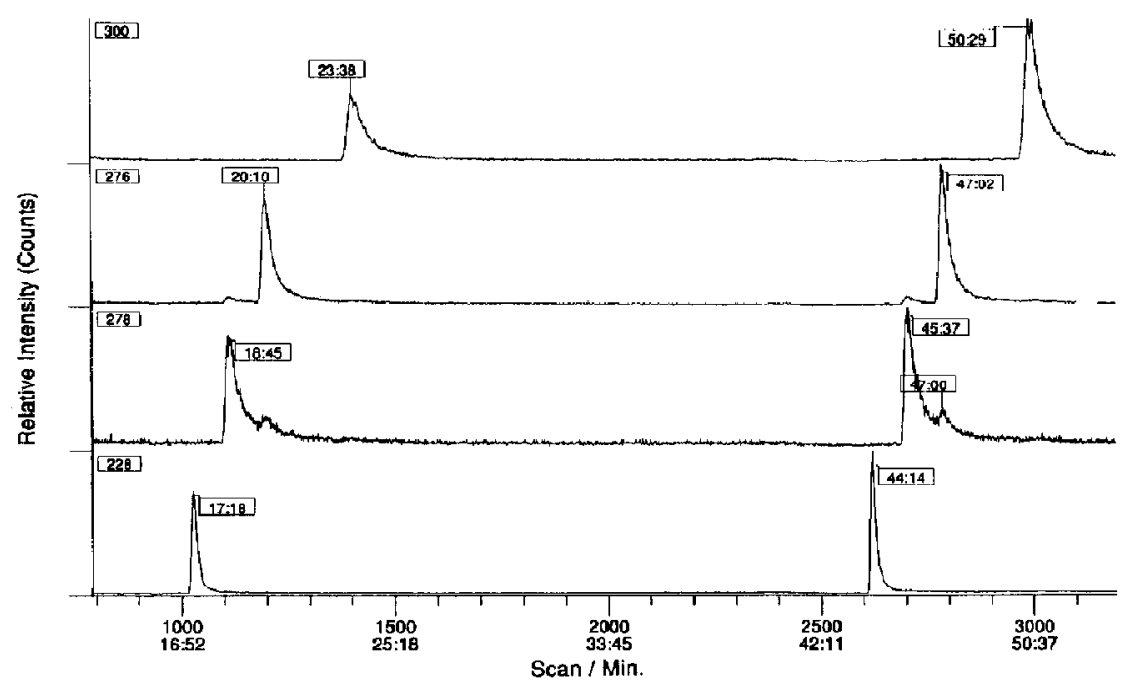

Figure 9. HPLC-PB mass chromatograms showing the separation of $5 \mathrm{ng}$ chrysene (228), $10 \mathrm{ng}$ dibenz $[a, h]$ anthracene (278), $10 \mathrm{ng}$ benzolg,h,i]perylene $(276)$, and $25 \mathrm{ng}$ coronene (300); column $=15 \mathrm{~cm} \times 2 \mathrm{~mm}, 3 \mu, \mathrm{C}-18$ silica; eluent for first chromatogram $=100 \% \mathrm{MeOH}$; eluent for second chromatogram $=\mathrm{MeOH}$ containing $0.05 \%$ ammonium acetate, flow rate $=0.3 \mathrm{~mL}$. $\min ^{-1}$. 


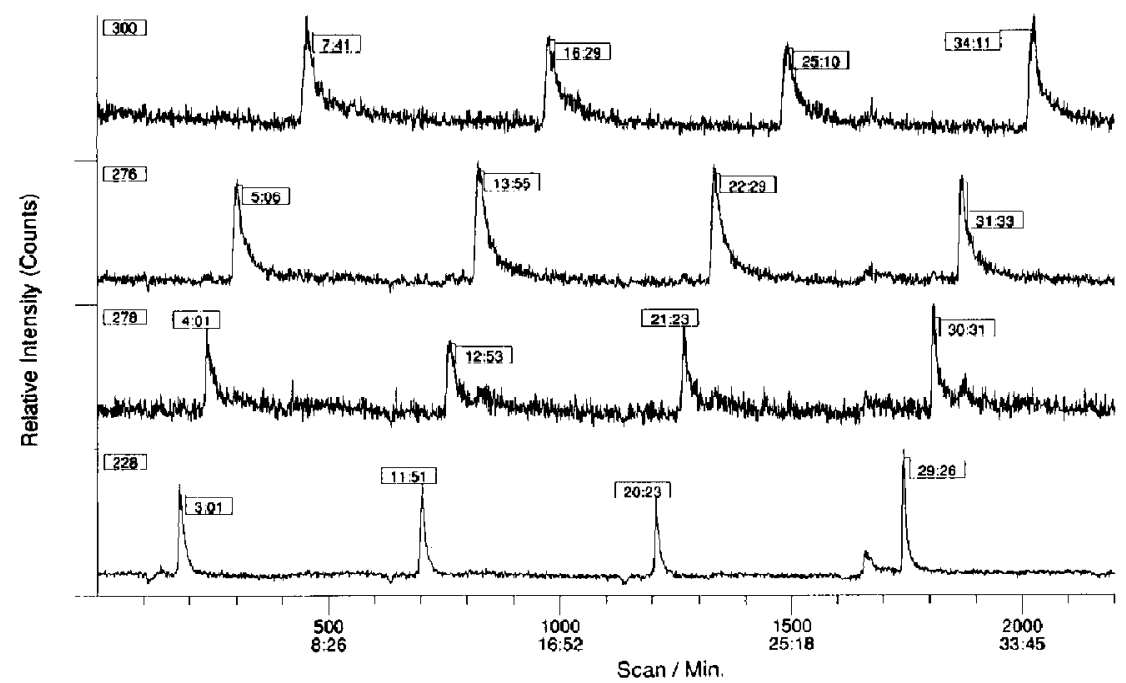

Figure 10. SIM trace of $0.5 \mathrm{ng}$ chrysene (228), $1 \mathrm{ng}$ dibenz[a,h]anthracene (278), $1 \mathrm{ng}$ benzo[g,h,i]perylene (276), and $2.5 \mathrm{ng}$ coronene (300) (first three chromatograms); last (fourth) chromatogram is SIM trace of $0.5 \mathrm{ng}$ chrysene (228), $1 \mathrm{ng}$ dibenz[a,h]anthracene (278), $1 \mathrm{ng}$ benzo[g,h,i]perylene (276), and $2.5 \mathrm{ng}$ coronene (300) in $10 \% \mathrm{MeCN}+90 \%$ tap water; column $=15$ $\mathrm{cm} \times 2 \mathrm{~mm}, 3 \mu$, C-18 silica; eluent-MeOH containing $0.05 \%$ ammonium acetate, flow rate $=0.3$ $\mathrm{mL} \min ^{-1}$.

ing $0.5 \mathrm{ng}(10 \mu \mathrm{L}$ of $50 \mathrm{ppb})$ chrysene, $1.0 \mathrm{ng}$ (10 $\mu \mathrm{L}$ of $100 \mathrm{ppb})$ dibenzo[a,h]anthracene and benzo[g,h,i]perylene, and $2.5 \mathrm{ng}(10 \mu \mathrm{L}$ of $250 \mathrm{ppb})$ coronene] but in $90 \%$ tap water and $10 \%$ acetonitrile instead of $100 \%$ acetonitrile.

\section{Calibration}

Figure 11 shows the calibration graphs for chrysene, dibenzo[ $\mathrm{a}, \mathrm{h}] \mathrm{anthracene,}$ and benzo[ $\mathrm{g}, \mathrm{h}, \mathrm{i}] \mathrm{perylene.} \mathrm{The}$ plots of area counts of the signals against the concentration is of chrysene, dibenzo[a,h]anthracene, and benzo[g,h,i]perylene generated straight-line calibrations over the range of concentrations investigated. The straight-line calibrations suggest that the

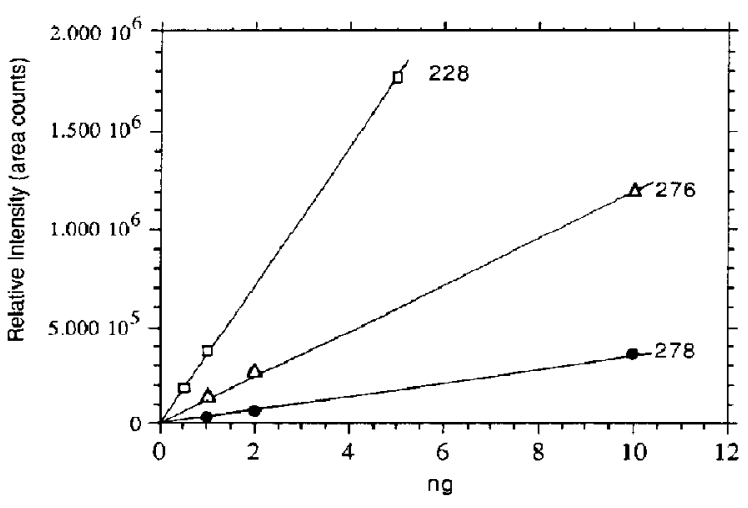

Figure 11. Calibration graphs for chrysene (228), dibenz [a,h]anthracene (278), and benzolg,h,i]perylene (276).
HPLC-PB-MS method reported here can be used for quantitative determination of PAHs.

\section{Discussion}

Although ultrasonic heads have been used for a long time for nebulizing effluents [43], Ligon and Dorn [31] were the first to use it in a PB interface. However, in our device, it was extremely difficult to keep good alignment among aerosol beam, nozzle, and three-stage momentum separator when HPLC effluent was delivered tangentially to the ultrasonic tip in the manner described by Ligon and Dorn [30]. With the concentric ultrasonic nebulizer, however, the alignment problem is eliminated.

From the literature [29-36], it is clear that the main limitation of the PB method is its poor sensitivity. In this article, we have shown that the HPLC-PB-MS method can detect nanogram amounts of high-molecular-weight PAHs. The sensitivity of the PAHs can be related to the intensity of their El spectra as well as to their high transfer rate into the mass spectrometry ion source. The transfer rate for chrysene was estimated at approximately $40 \%$ based on the solid probe-EI and PB-MS-EI determinations. The detection limit obtained by the method described here for chrysene is comparable to HIPLC with fluorescent detection [43].

Since a direct comparison of detection limit for chrysene or other PAHs with other PB interfaces was not possible, we determined the detection limits for carbaryl, which had previously been published. Using a Hewlett-Packard 59980A PB interface, Pleasance et al. [27] have reported a detection limit of $10 \mathrm{ng}$ for 
carbaryl under SIM acquisition conditions. Using the system described in this article, detection of about $1 \mathrm{ng}$ carbaryl is possible under SIM conditions. Hence, the $\mathrm{PB}$ interface with a concentric pneumatic ultrasonic nebulizer, described in this work, is more sensitive compared with a commercially available PB interface with a concentric pneumatic nebulizer. This may be due to a better transfer rate of solutes through this PB interface than others, as very low transfer rates for some solutes through commercially available PB interfaces are reported in the literature [44].

In conclusion, the HPLC-PB-MS method reported here has revealed high sensitivity for PAHs. The high sensitivity of the method for PAHs with molecular weights $>178$ can be exploited in developing a HPLC-PB-MS method, complementary to the popular GC-MS method, for the determination of high-molecular-weight PAHs.

\section{Acknowledgments}

We thank the Ontario Ministry of the Environment and Energy for funding this work under the Research Advisory Committee (Grant 1384). The authors are also thankful to John Rustenberg, Meinhart Benkel, Jim Ross, and Tony Biernacki of the Technical Services Shops of Brock University for the machining and electronics of the particle-beam interface. The Natural Science and Engineering Research Council of Canada (NSERC) is thanked for an equipment grant for the purchase of a Kratos mass spectrometer.

\section{References}

1. Uthe, J. F. Canadian Chem. News 1991 (Aug), 25-27.

2. Christensen, E. R.; Zhang, X. Environ. Sci. Technol. 1993, 27, 139-146.

3. Tan, Y. L.; Quanci, J. F.; Borys, R. D.; Quancy, M. J. Atmos. Enoiron. 1992, 26A, 1177-1181.

4. Brindle, I. D.; Li, X-F. J. Chromatogr. 1990, 498, 11-24.

5. Ogan, K.; Katz, E.; Slavin, W. Anal. Chem. 1979, 51, 1315-1320.

6. Wise, S. A.; Benner, B. A.; Byrd, G. D; Chesler, S. N.; Rebbert, R. E.; Schantz, M. M. Anal. Chem. 1988, 60, 887-894.

7. Robbat, A. Ir.; Liu, T-Y; Abrahm, B. M. Anal. Chem. 1992, 64, $1477-1483$

8. Lee, M. L.; Novotny, M.; Bartle, K. D. Anal. Chern. 1976, 48 , 405-416.

9. Lee, M. L.; Novotny, M.; Bartle, K. D. Arul. Chtrn. 1976, 48, $1566-1572$.

10. Nowicki, H. G.; Kieda, C. A.; Bassett, D. O. In Polynuclear Aromatic Hydrocarbons: Chemical and Biological Effects; Bjorseth. A.; Dennis, A. J., Eds.; Battelle: Columbus, $\mathrm{OH}_{\text {, 1980; pp }}$ $75-87$.

11. Covey, T. R,; Lee, E. D.; Bruins, A. P.; Henion, J. D. Anal. Chem. 1986, 58, 1451A-1461A.

12. Arpino, P. J. J. Chromatogr. 1985, 325, 3-11.

13. Arpino, P. J.; Guiochon, G. Anal. Chem. 1979, 51, 682A-701A.
14. Tsuda, T.; Keller, G.; Stan, H-J. Anal. Chem. 1985, 57, $2280-2282$.

15. Blaklcy, C. R.; Vestal, M. L. Anal. Chem. 1983, 55, 750-754.

16. Hayward, M. J.; Snodgrass, J. T.; Thomson, M. L. Rapid Commun. Mass Spectrom. 1993, 7, 85-91.

17. Abian, J.; Stone, A.; Marrow, M. G.; Creer, M. H.; Fink, L. M.; Lay. J. O. Jr. Rapid Commun. Mass Spectrom. 1992, 6, 684-689.

18. Bean, M. F.; Pallante-Morell, S. L.; Dulik, D. M.; Fenselat, C. Anai. Chem. 1990, 62, 121-124.

19. Barcelo, D. Org. Mass Spectrom. 1989, 24, 898-902.

20. Arpino, P. Mass Spectrom. Rev. 1992, 11, 3-40.

21. Whitehouse, C. M.; Dreyer, R. N.; Yamashita, M.; Fenn, J. B. Antal. Chem. 1985, 57, 675-679.

22. Lin, H-Y; Voyksner, R. D. Anal. Chem. 1993, 65, 451-458.

23. Lee, E. D.; Henion, J. D. Rapid Commun. Mass Spectrom. 1992, 6, 727-733.

24. Covey, T. R.; Lee, E. D.; Henion, J. D. Anal. Chem. 1986, 58, $2453-2460$.

25. Horning, E. C.; Carroll, D. I.; Dzidic, I.; Heagle, K. D.; Horning, M. G.; Stillwell, R. N. J. Chromatogr. Sci. 1974, 12, 725-729.

26. Deorg, D. R.; Bajic, S. Rapid Commun. Mass Spectrom. 1992, 6, 663-666.

27. Pleasance, S.; Anacleto, J. F.; Bailey, M. R.; North, D. H. I. Am. Soc. Mass Spectrom. 1992, 3, 378-397.

28. Henion, J. D.; Thomson, B. A.; Dawson, P. H. Anal. Chem. 1982, 54, 451-456.

29. Browner, R. F.; Winkler, P. C.; Perkins, D. D.; Abby, L. E. Microchem. I. 1986, 34, 15-24.

30. Winkler, P. C.; Perkins, D. D., Williums, W. K.; Browner, R. F. Anal. Chem. 1988, 60, 489-493.

31. Ligon, W. V. Jr.; Dorn, S. B. Anal. Chem. 1990, 62, 2573-2580.

32. Deorge, D. R., Burger, M. W; Bajic, S. Anal. Chem. 1992, 64, 1212-1216.

33. Behymer, T. D.; Bellar, T. A.; Budde, W. L. Anal. Chem. 1992, 62, 1686-1690.

34. Kim, I. S.; Sasinos, F. I.; Stephens, R. D.; Brown, M. A. J. Agric. Food Chem. 1990, 38, 1223-1226.

35. Deorge, D. R.; Miles, C. J. Anal. Chem. 1991, 63, 1999-2001.

36. Hsu, J. AnuL. Chem. 1992, 64, 434-443.

37. Galimberti, R.; Lecchi, P.; Angelis, L. D.; Caruso, D.; Toia, A. V.; Racagni, G. Anal. Biochem. 1992, 201, 356-361.

38. Voyksner, R. D.; Smith, C. S.; Knox, P. C. Biomed. Environ. Mass Spectrom. 1990, 19, 523-534.

39. Miles, C. J.; Deorge, D. R.; Bajic, S. Arch. Environ. Contam. Toxicol. 1992, 22, 247-251.

40. Ho, J. S.; Beymer, T. D.; Budde, W. L.; Bellar, T. A. J. Am. Soc. Mass Spectrom. 1992, 3, 662-671.

41. Donnelly-Betowsky, L.; Pace, C. M.; Roby, M. R. J. Am. Soc. Mass Spectrom. 1992, 3, 823-830.

42. Olson, K. W.; Haas, W. J. Jr.; Fassel, V. A. Anal. Chem. 1977, 49, 632-637.

43. Method HPLC/L-X3HIDI, The Determination of Polynuclear Aromatic Hydrocarbons in Surface Water, Domestic Waters, and Industrial Wastes by HPLC; Ontario Ministry of the Environment: Rexdale, Ontario, 1988.

44. Tinke, A. P.; Van Der Hoeven, R. A. M.; Niessen, W. M. A.; Tjaden, U. R.; Vander Greef, J. J. Chromatogr. 1991, 554, 119-124. 